\title{
Morphological and Pomological Variability Analysis of Wal- nut (Juglans regia L.) Genetic Resources from the Middle and High Atlas of Morocco
}

\author{
Ghizlane Kabiri, Said Bouda*, Mohamed Elhansali, and Abdelmajid Haddioui
}

Laboratory of Biotechnologies and Valorization of Plant Gnetic Resources, University of Sultan Moulay Slimane, Faculty of Sciences and Techniques, P.B. 523, Beni Mellal, Morocco

Received: October 12, 2018 / Accepted: December 1, 2018

\section{Abstract}

The walnut (Juglans regia $L_{\text {. }}$ ) is conducted yet as a traditional fruit crop in different environments of Moroccan mountains. Besides, little data is available on its genetic diversity. Thus, twenty-one morphological and pomological characters of 11 Moroccan accessions were used to assess phenotypic variation of this species. Significant differences were found between accessions for the most examined traits, indicating a high phenotypic diversity. Multivariate analyses lead to identify three groups of accessions. The first group composed by the accessions of both Middle and High Atlas Mountain with high weight and percentage of kernel and low thickness of shell. The second group is made of accessions from the High Atlas Mountain characterised by large leaf, high nut dimension and large nut size. The third group is composed of two accessions; one belongs to the Middle Atlas Mountain and the other originating from High Atlas Mountain and characterized by small leaf and nut. Then, the structuration of accessions in three groups was not correlated to the mountain range type. So, this study showed a significant phenotypic heterogeneity between the eleven studied accessions which opens the way for the strategies for their conservation and the selection of efficient genotypes with the desired traits.

Keywords: Walnut; Juglans regia L; Morocco's accessions; Leaf variability; Fruit variability.

\footnotetext{
*Corresponding author: saidbouda@yahoo.fr
}

\section{Introduction}

The walnut species (Juglans regia L.) is one of the most widely cultivated and economically important species of edible nuts in the temperate regions of the world (McGranahan and Leslie, 1990). This species is originated from areas of Central Asia (Amiri et al., 2010) and its cultivation and production were centered in USA and China (Angmo et al., 2013). Throughout history, the nuts have been a staple food providing energy, protein, essential fatty acids, vitamins and minerals. They are also being investigated for their potential health benefits (Dreher et al., 1996). The walnut tree has a great nutritional value and the noble wood. Moreover, walnuts have significant economic value and medicinal importance for human health, because of their biochemical composition of polyunsaturated fatty acids, especially linoleic acid and alpha-linolenic and protein value (Savage et al., 2001).

The first introduction of this species, as a traditional fruit crop, to the great Maghreb was attributed to the Romans (Germain, 1992). In Morocco, walnut trees cover an area of 7600 $\mathrm{Ha}$ and are cultivated in different environments (Lansari et al., 2001). The trees can be found in humid and warm conditions, in the Rif and Atlas Mountains (High and Middle Atlas) and in arid regions in Southeastern Morocco. More than half of the plantings resulted from the prevailing way of seed propagation practiced by farmers, since grafting is less adopted (Lansari et al., 2001). Genetic research on Moroccan Juglans regia has received little attention and few studies have concerned its genetic diversity. Only one study of phenotypic variability of few South-Eastern populations was carried out by Kodad et al. (2014). Consequently, it would be very interesting to find more 
discriminating criteria that could provide additional information on genetic diversity of Moroccan walnut populations. Thus, the present study was conducted to characterize and evaluate the genetic variability of walnut accessions using some morphological and pomological traits and to look for any space structuring of such accessions according to their distribution on the Atlas Mountains in Morocco.

\section{Materials and Methods}

\section{Plant Material and Phenotyping Traits}

During September 2014, fresh leaves and mature nuts were collected from eleven Moroccan accessions representing the main cropping area of walnut. Table 1 and Figure 1 present the accessions investigated as well the characteristics of their geographical and ecological origins. For each accession, 10 trees were randomly chosen and sampled. From each tree, ten developed leaves and 20 nuts were collected from different sites and elevation of the tree to be subject of observations and measurements considered in the present study.
According to the IPGRI and UPOV descriptors (IPGRI, 1994; UPOV, 1999), 31 parameters related to leaves and fruits (Table 2) were considered, following instructions given by the IPGRI and UPOV descriptors. All traits on the kernel have been measured one month after harvest when the water content was below 8\% (UPOV, 1999).

\section{Statistical Analyses}

The obtained data was submitted to Analysis of variance (ANOVA) to search for any significant differences among accessions for the parameters analyzed. When significant differences occurred among accessions, a LSD test was used to determine if there were significant differences between individual accessions. Association between traits was established using Pearson correlation coefficient. All these analyses were performed by using Statistical Analysis System program (SAS, 1999). Accessions ordination and classification were performed using the principal component analysis (PCA)( XLSTAT, 2015) and the hierarchical cluster analysis (Statistica StatSoft, 1997). The PCA and the cluster analyses were carried out on the matrix of mean values of measured characters.

Table 1. Geographic origin and ecological characteristics of the 11 walnut (Juglan rejia L.) accessions.

\begin{tabular}{|c|c|c|c|c|c|c|c|}
\hline Accessions & Code & Geographic Origin & $\begin{array}{c}\text { Altitude } \\
\text { (m) }\end{array}$ & $\begin{array}{c}\text { Latitude } \\
\mathbf{N} \\
\end{array}$ & $\begin{array}{c}\text { Longitude } \\
\text { W } \\
\end{array}$ & Zone & $\begin{array}{c}\text { Rainfall } \\
\text { Average }(\mathrm{mm})\end{array}$ \\
\hline Aghbala & $\mathrm{AGH}$ & $32 \mathrm{Km}$ North East of Aghbala & 1673 & $32^{\circ} 32^{\prime}$ & $5^{\circ} 39^{\prime}$ & Middle Atlas & 450 \\
\hline Naour & NAO & Central Naour & 1300 & $32^{\circ} 29^{\prime}$ & $5^{\circ} 58^{\prime}$ & Middle Atlas & 600 \\
\hline Taghzirte & TAG & $12 \mathrm{Km}$ East of Tagzirte & 650 & 3226 & $6^{\circ} 12^{\prime}$ & Middle Atlas & 700 \\
\hline Ait Bougamez & $\mathrm{ABZ}$ & Ait Bougamez Centre & 1996 & $31^{\circ} 38^{\prime}$ & $6^{\circ} 28^{\prime}$ & High Atlas & 580 \\
\hline Ait M'hamed & AMD & $20 \mathrm{Km}$ South East of Azilal & 1728 & $31^{\circ} 25^{\prime}$ & $2^{\circ} 28^{\prime}$ & High Atlas & 450 \\
\hline Demnate & DEM & $3 \mathrm{~km}$ South East of Demnate & 932 & $31^{\circ} 43^{\prime}$ & $6^{\circ} 58^{\prime}$ & High Atlas & 350 \\
\hline Imlil & IML & $17 \mathrm{~km}$ South of Asni & 1763 & $31^{\circ} 8^{\prime}$ & $7^{\circ} 55^{\prime}$ & High Atlas & 459 \\
\hline Anougal & ANG & $40 \mathrm{~km}$ South of Amzmiz & 1569 & $31^{\circ} 9^{\prime}$ & $8^{\circ} 15^{\prime}$ & High Atlas & 681 \\
\hline Beram & BER & $5 \mathrm{~km}$ South of Midelt & 1521 & $32^{\circ} 40^{\prime}$ & $4^{\circ} 44^{\prime}$ & High Atlas & 210 \\
\hline Amouguer & $\mathrm{AMG}$ & $40 \mathrm{~km}$ West of Rich & 1569 & $32^{\circ} 12^{\prime}$ & $5^{\circ} 8^{\prime}$ & High Atlas & 250 \\
\hline Tabrijiate & TBR & $70 \mathrm{~km}$ East of Imilchil & 1831 & $32^{\circ} 16^{\prime}$ & $4^{\circ} 56^{\prime}$ & High Atlas & 319 \\
\hline
\end{tabular}

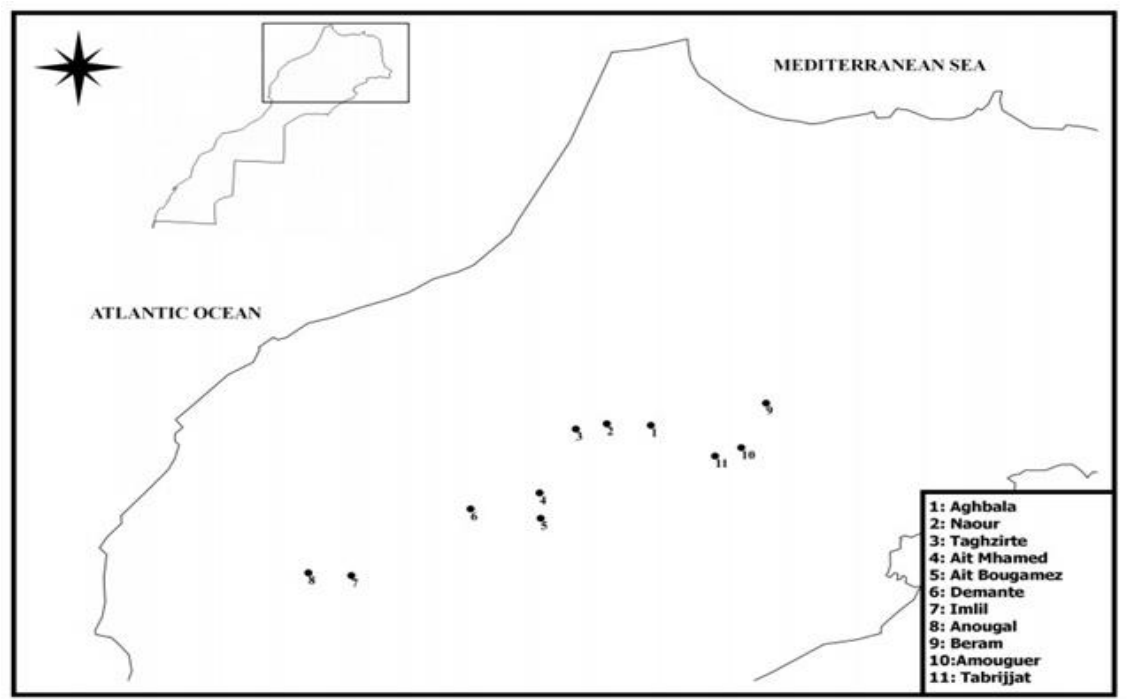

Figure 1. Morocco map showing sampling sites of the analyzed walnut accessions. 
Table 2. Morphological and pomological traits analyzed in the 11 walnut accessions.

\begin{tabular}{llll}
\hline -Leaf traits & & Width of Pad on Suture & WPS \\
Leaf Length & LL & Prominence of Pad on Suture & PPS \\
Leaf Width & LW & Shape of Base Perpendicular to Suture & SBPS \\
Number of Leaflet & Nlet & Shape of Apex Perpendicular to Suture SAPS \\
Leaflet Shape & LetS & Prominence of Apical Tip & PAT \\
Leaflet Width & LetW & Structure of Surface of Shell & SSSh \\
Leaflet Length & LetL & Shell Colour & ShC \\
Leaflet Margin & LetM & Shell Strength & ShS \\
Leaf Colour & LC & Adherence of Two Halves of Shell & ATHSh \\
Rachis Colour & RC & Thickness of Shell & TSh \\
-Nut traits & & - Kernel traits & \\
Nut Shape in Longitudinal section through Suture & NSLS & Ease of Removal of Kernel & ERK \\
Nut Shape in Longitudinal section Perpendicular to Suture & NSLPS & Kernel Weight & KW \\
Nut Width & NW & Kernel Percentage & KP* \\
Nut Length & NL & Kernel Fill & KF \\
Nut Weight & NW & Kernel Colour & KC \\
Nut: Position of Pad on Suture & NPPS & Kernel Flavor & KFV \\
\hline
\end{tabular}

Kernel percentage $=$ Kernel weigh/nut weight $* 100$

\section{Results}

Mean values of morphological and pomological characters measured and their standard deviations are presented in Table 3. Results of analysis of variance indicated significant differences between accessions for all parameters except number of leaflets and leaflet margin.

\section{Leaf Morphological Traits}

Morphological traits related to leaf show large variability between accessions. In fact, leaf length varied among accessions from $37.98 \mathrm{~cm}$ for Aghbala to $44.25 \mathrm{~cm}$ for Anougal with an average of $41.52 \mathrm{~cm}$, the leaf width, with a general mean of $25.85 \mathrm{~cm}$, ranged from $24.46 \mathrm{~cm}$ for Taghzirte to $27.17 \mathrm{~cm}$ for Beram and the number of leaflets scaled from 7.38 for Naour to 8.75 for Taghzirte with an average of 8.24. In addition, leaflet length, having an average of $10.75 \mathrm{~cm}$, varied from $9.37 \mathrm{~cm}$ for Taghzirte to $11.16 \mathrm{~cm}$ for Imlil. With a general mean of 5.48 $\mathrm{cm}$, the highest value of leaflet width was recorded in Tabrijjate $(6.22 \mathrm{~cm})$ and the lowest was observed in Taghzirte $(4.98 \mathrm{~cm})$. However, the number of leaflets per leaf has varied narrowly among accessions, within a range of 7.3 for Naour to 8.75 for Taghzirte, and averaged 8.24. Furthermore, with an entire leaflet margin for almost all, the accessions did not show any difference for this trait. In general, the color of leaf was green with a rachis color varied between green, yellow to red.

\section{Fruit Pomological Traits}

The nut weight for the accessions tested varies within the range of $8.26 \mathrm{~g}$ for Aghbala to $10.20 \mathrm{~g}$ for Tabrijjate, with an average of $9.48 \mathrm{~g}$. The average nut length was $35.46 \mathrm{~mm}$ and ranged from $32.08 \mathrm{~mm}$ for Demnate to $38.11 \mathrm{~mm}$ for Imlil. For nut width, the lowest value was obtained for Demnate (27.39 $\mathrm{mm})$ and the highest for Tabrijjate $(31.50 \mathrm{~mm})$ with a mean of $30.10 \mathrm{~mm}$. The shell thickness of the studied accessions in this investigation varied between $1.33 \mathrm{~mm}$ for Amouguer and $1.83 \mathrm{~mm}$ for Ait M'hamed with a value of $1.60 \mathrm{~mm}$ as average. Regarding the kernel weight, the highest value was observed in Amouguer (4.13 g), while the least was obtained for Aghbala $(2.86 \mathrm{~g})$, with a mean of $3.71 \mathrm{~g}$. The kernel percentage ranged from $33.65 \%$ in Demnate to $43.76 \%$ in Amouguer and averaged $38.28 \%$. For nut shape, in general, it was elliptic board with a medium shell color and intermediate shell strength. Concerning kernel color, $9 \%$ of the walnut accessions were revealed with light kernel, 36\% with amber kernel and 55\% with light amber kernel. For kernel flavor, it was revealed satisfactory for all walnut accessions. For the remaining analyzed traits, they have varied widely among accessions indicating the existence of high pomological variability in Moroccan walnut germplasm.

\section{Association Between Parameters Studied}

Correlation among all morphological and pomological traits is summarized in table 4. The strongest negative correlations were observed between, on one hand, kernel weight (KW) and, on the other hand, leaf length, (LL), leaf width (LW), leaflet length (LetL), nut length (NL), nut weight (NW), shape of base perpendicular to suture (SBPS) and kernel colour (KC), with respective coefficients of $-0.95,-0.93,-0.93,-0.92,-0.91,-0.95$ and -0.96 . However, strong positive correlations were found between kernel weight (KW) and number of leaflet (Nlet) $(\mathrm{r}=0.97)$, nut shape (NSLPS) $(\mathrm{r}=0.97)$, prominence of apical 


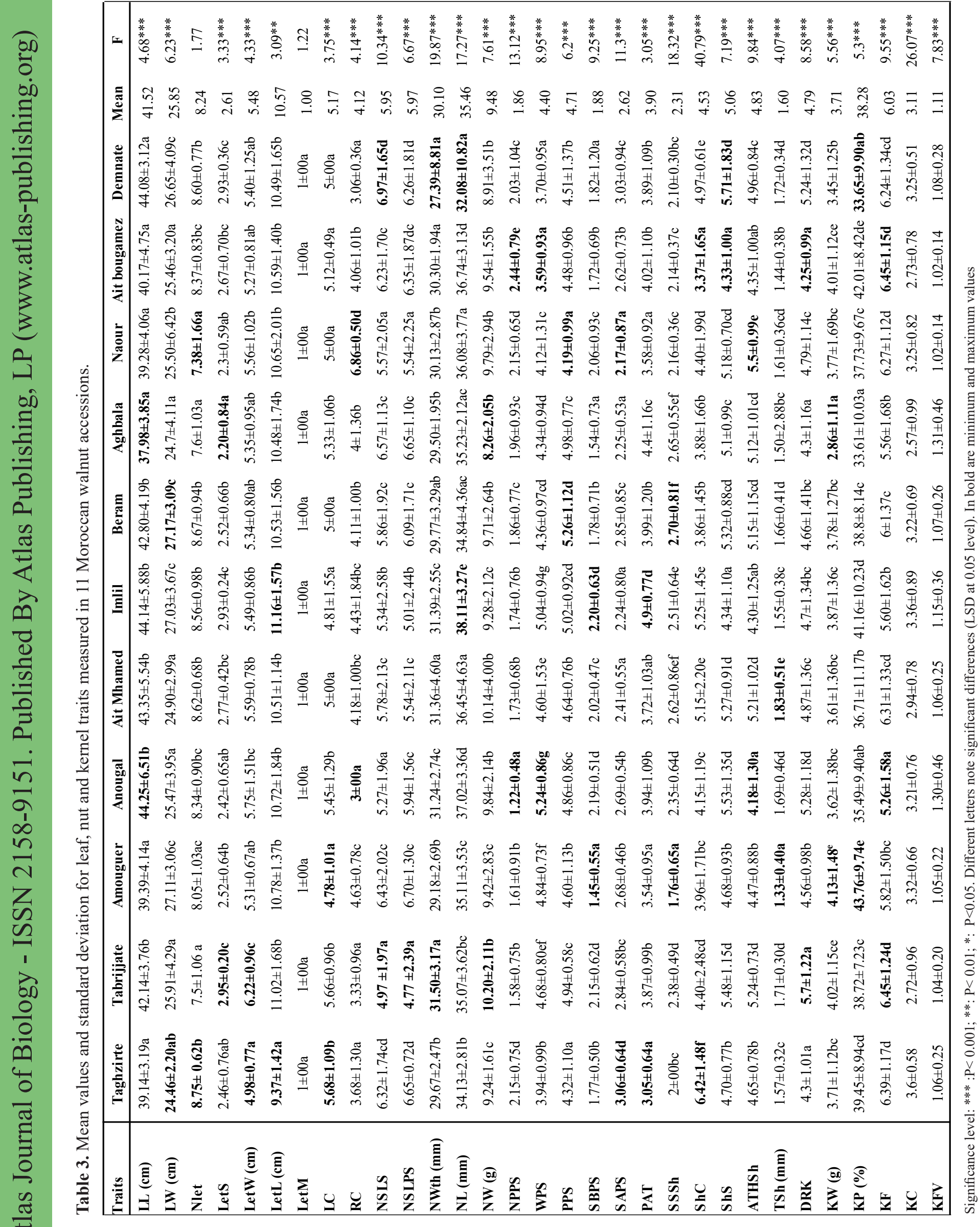




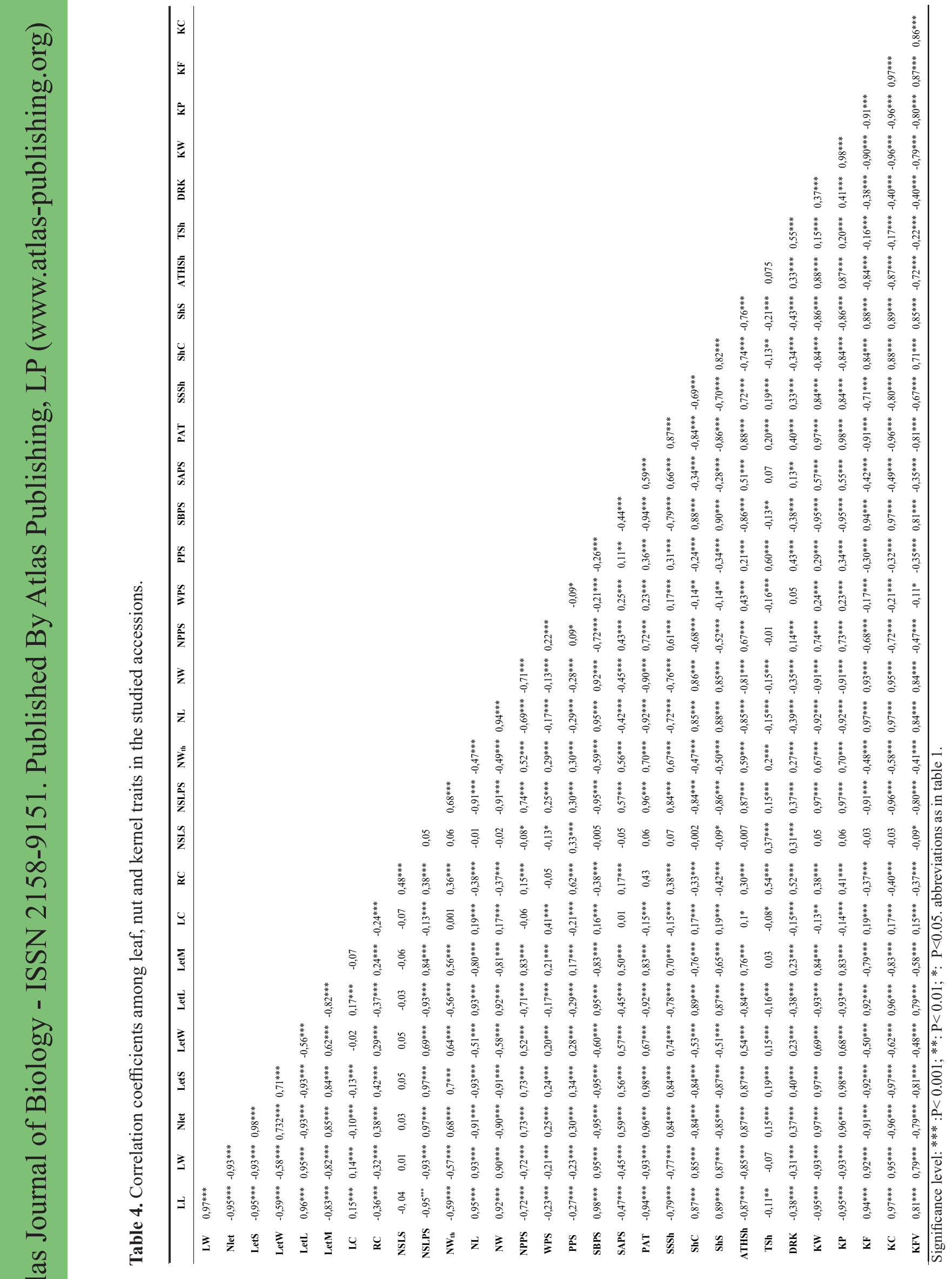


tip (PAT) $(r=0.97)$ and kernel percentage (KP) $(r=0.98)$. Furthermore, nut weight $(\mathrm{NW})$ was revealed to be positively and strongly correlated with leaf length (LL) $(r=0.92)$, leaf width (LW) $(\mathrm{r}=0.90)$, leaflet length (LetL) $(\mathrm{r}=0.92)$, nut length $(\mathrm{NL})$ $(\mathrm{r}=0.94)$, shape of base perpendicular to suture (SBPS) $(\mathrm{r}=0.92)$, kernel fill (KF) ( $\mathrm{r}=0.93)$ and kernel colour $(\mathrm{KC})(\mathrm{r}=0.95)$, while it has a negative correlation with number of leaflet (Nlet) $(\mathrm{r}=-$ $0.90)$, shape of nut (NSLPS) $(\mathrm{r}=-0.91)$, prominence of apical tip (PAT) $(\mathrm{r}=-0.90)$, kernel weight $(\mathrm{KW})(\mathrm{r}=-0.91)$ and kernel percentage $(\mathrm{KP})(\mathrm{r}=-0.91)$.

\section{Multivariate Analysis}

The eigenvalues obtained by principal component analysis (PCA) indicate that the first two components provide a good summary of the data. They explained $71.29 \%$ of the total variation with each component explaining respectively $45.88 \%$ and $25.41 \%$. The first component is defined negatively by weight and length of nut, color and fill of kernel and by length and width of leaf; and positively by weight and percentage of kernel and by shape and number of leaflet. The second component is positively correlated to thickness of shell, ease of removal the kernel and the color of rachis. Figure 2 illustrated accessions on the plot of the first two axis spaces, shows that accessions may constitute three groups. The first one is composed of two accessions of Middle Atlas Mountain: Naour (NAO) and Taghzirte (TAG) and two other accessions of High Atlas: Ait Bougamaz (ABZ) and Amouguer (AMG), characterized by high weight and percentage of kernel and low thickness of shell. The second group is made of five accessions of High Atlas Mountain namely Ait M'hamed (AMD), Imlil (IML), Beram (BER), Tabrijjate (TAB) and Anougal (ANG), characterized with large leaf, high nut dimension and large nut size. The third group is composed of two accessions; one belongs to Middle Atlas (Aghbala, (AGH)) and the other arising from High Atlas (Demnate (DEM)) which are characterized by small leaf and nut.

Hierarchical cluster analysis identified three distinct groups (Figure 3) confirming the PCA results. The first group is composed of Taghzirte (TAG) and Naour (NAO) accessions originating from Middle Atlas Mountain and Amouguer (AMG) and Ait Bougamaz (ABZ) coming from High Atlas Mountain. The second group includes Ait M'hamed (AMD), Imlil (IML), Barem (BAR), Tabrijjate (TBR) and Anougal (ANG) accessions, all belonging to High Atlas Mountain. The Demnate (DEM) and Aghbala (AGH) accessions represented the third group and seem to diverge significantly from the others.

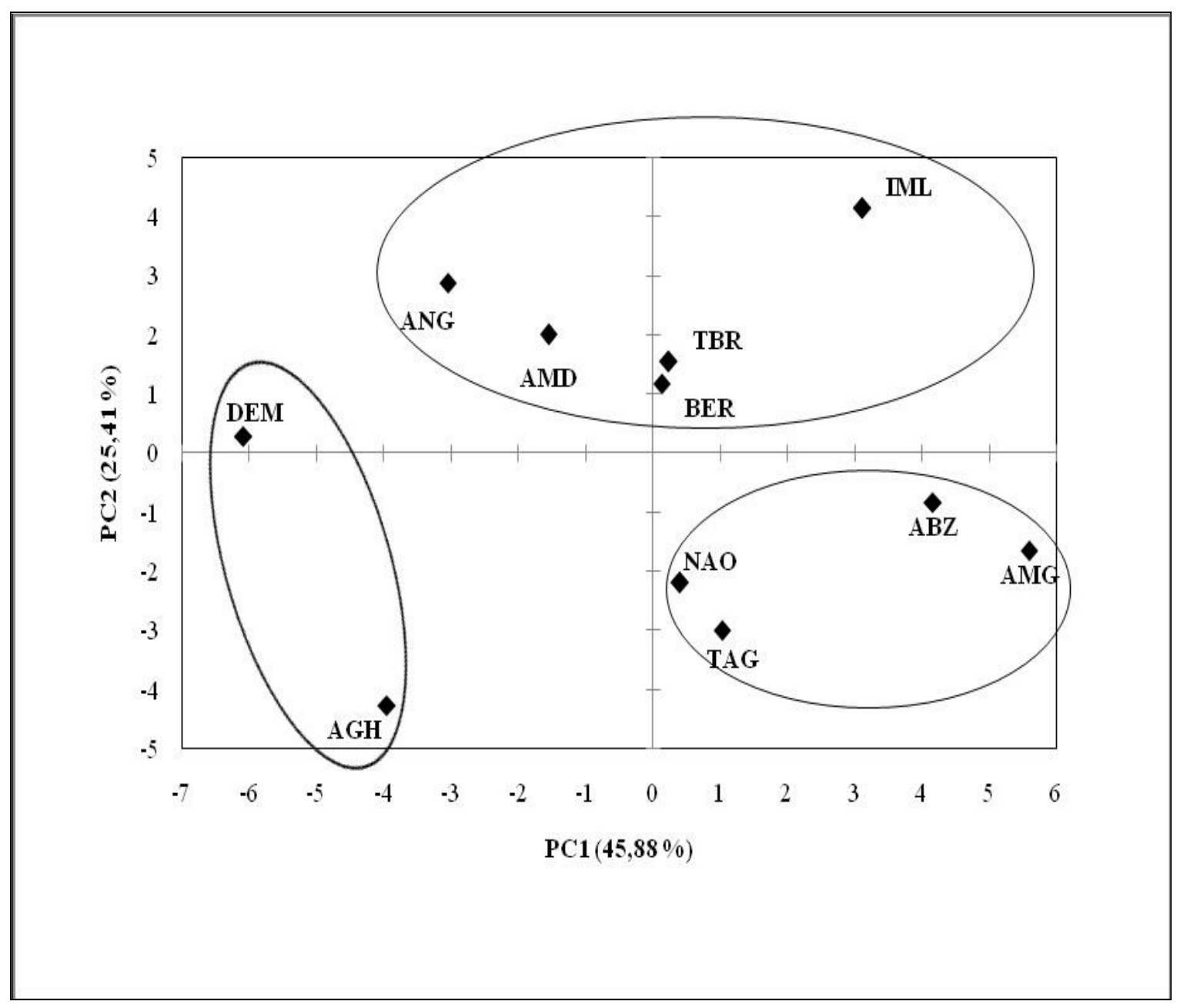

Figure 2. Plot on the two first principal components of 11 walnut accessions. Abbreviations as in table 1. 


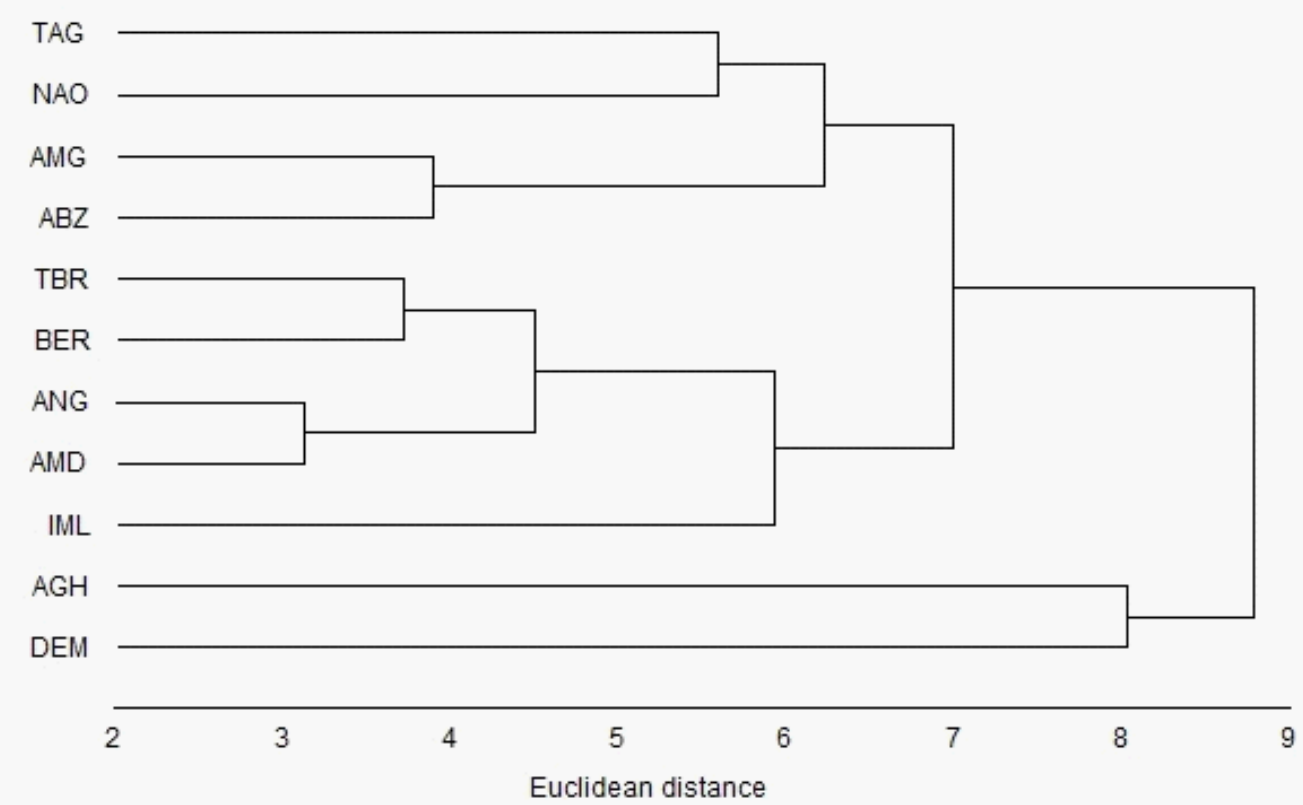

Figure 3. Dendrogram of 11 Moroccan walnut accessions based on morphological and pomological traits. Abbreviations as in table 1.

\section{Discussion}

The results of this study show that the accessions studied could be a very interesting source of walnut genetic diversity. The majority of morphological traits of leaves showed a great difference among walnut accessions, especially for the length and width of leaf. Furthermore, the pomological traits exhibited the highest variability among accessions, which was established for most of nut and kernel traits.

According to consulted literature, nut weight, kernel percentage and color of kernel have been considered as the most important indices of quality and economic yield in walnut trees, which should be further investigated. In the Moroccan accessions studied, the nut weight varied from 8.26 to 10.20 g. Values that are within the consulted literature are found between 6 and $16.89 \mathrm{~g}$ in Iranian genotypes (Arzani et al., 2008; Ghasemi et al., 2012; Ahandani et al., 2014), 7.46 and $15.21 \mathrm{~g}$ in Turkish genotypes (Karadag and Akça, 2011) and from 6.9 to $16.27 \mathrm{~g}$ in Romanian walnut (Cosmulescu, 2013). In addition, Moroccan accessions have an average kernel percentage between $33.65 \%$ and $43.76 \%$. These values are lower than those obtained for some walnut genotypes from Turkey (46.15 to $63.16 \%$ ) (Karadag and Akça, 2011) and Iran (48 to 59\%) (Ahandani et al., 2014). According to color of kernel, our result showed that $55 \%$ of the walnut accessions investigated were revealed with light amber kernel. This result is in accordance with that reported in Iranian genotypes by Arzani et al. (2008), finding $52 \%$ of genotypes with light amber kernel. In fact, the light kernel color is a primary breeding objective for walnut. On other hand, the shell thickness of the Moroccan accessions analysed in this work varied from 1.33 to $1.83 \mathrm{~mm}$, which is in agreement with that obtained by Karadag and Akça (2011) $(0.95$ to $1.60 \mathrm{~mm})$ and Akça et al. (2015) $(1.11$ to $2.33 \mathrm{~mm})$ in Turkish walnut, but greater than that reported by Sharma et al. (2014) in Indian walnut (1.24 mm).

These results showed a considerable phenotypic diversity in the Moroccan walnut germplasm in comparison to that of other countries. This variability may be due, first, to genotypic variation or environmental conditions (Ghasemi et al., 2012). Second, walnuts species are monoecious and heterodichogamous, favoring outcrossing over selfing (Ebrahimi et al., 2016). Third, reproduce by seeds of this species causes a very important genetic variability that appears at the flowering period for pomological characters, vigor of the tree and type of fructification, which allowed each geographic region to maintain a diverse population (Lansari et al., 2001). Besides, Diaz et al. (2005) stated that the geographic location and the growing conditions affect fruit and kernel traits of walnut populations from western Spain.

\section{Conclusion}

These results show that Moroccan walnut presents a high variability in comparison to that of others countries with similar ecological conditions. This investigation showed significant differences among accessions, permitting discrimination between them according to morphological traits related to leaf, nut and kernel. These findings should be exploited to select the best walnut accession with the wanted traits to be multiplied in order to encourage the agriculture and raise the production of walnut. Taking into account the relevance of high kernel weight, kernel percentage and low thickness of shell, the wal- 
nut accessions from Amouguer and Imlil should be considered as the first accessions to be useful as seed sources or multiplied vegetatively for walnut propagation in Morocco. It is obvious that survey of genetic diversity in Moroccan walnut using biochemical and molecular markers are projected and would be a complement for this study.

\section{References}

Ahandani EA, H Ramandi, J Sarmad, M samani, A Yavari and RA Ahandani (2014) Evaluation of Morphological Diversity among Some Persian Walnut Accessions (Juglans regia L.) In Guilan, Northern Iran. International Journal of Biotechnology 5(2): 21-30.

Akca Y, Y Bilgen and S Ercisli (2015) Selection of Superior Persian Walnut (Juglans regia L.) from Seedling Origin in Turkey. Acta Scientiarum Polonorum Hortorum Cultus 14(3): 103-114.

Amiri R, K Vahdati, S Mohsenipoor, MR Mozaffari and Ch Leslie (2010) Correlations between Some Horticultural Traits in Walnut. Horticultural Science 45(11): 1690-1694.

Angmo S, P Acharyya and MA Hasan (2013) Performance of Indigenous Walnut Selections under Climatic Conditions of Ladakh. International Symposium on Agri-Foods for Health and Wealth. Bangkok, Thailand, p.167-176.

Arzani K, H Mansouri-Ardakan, A Vezvaei and MR Roozban (2008) Morphological Variation among Persian Walnut (Juglans regia L.) Genotypes from Central Iran. New Zealand Journal of Crop and Horticultural Science 36: 159-168.

Cosmulescu S (2013) Phenotypic Diversity of Walnut (Juglans regia L.) in Romania - Opportunity for Genetic Improvement. South Western Journal of Horticulture, Biology and Environment 4(2): 117-126.

Diaz R, E Alonso and J Fernadez-Lopez (2005) Genetic and Geographic Variation in Seed Traits of Common Walnut (Juglans regia L.) among Twenty Populations from the West of Spain. Acta Horticultura 705: 137-141.
Dreher M, CV Maher and P Kearney (1996) The Traditional and Emerging Role of Nuts in Healthful Diets. Nutrition Reviews 54(8):241-245.

Ebrahimi A, A Zarei, Sh Lawson, K Woeste and MJM Smulders (2016) Genetic Diversity and Genetic Structure of Persian walnut (Juglans regia L.) Accessions from 14 European, African, and Asian Countries using SSR Markers. Tree Genetics and Genomes 12:114.

Germain E (1992) Le noyer. In: Amélioration des Espèces Végétales Cultivées, Objectifs et Critères de Sélection, INRA Editions. Paris, p. 620-632.

Ghasemi M, K Arzani and D Hassani (2012) Evaluation and Identification of Walnut (Juglans regia L.) Genotypes in Markazi Province of Iran. Cell Biology,; 2(2): 119-124.

IPGRI, (1994) Descriptors for walnut (Juglan spp.). International Plant Genetic Resources Institute, Rome, Italy.

Karadağ H and Y Akça (2011) Phenological and Pomological Properties of Promising Walnut (Juglans regia L.) Genotypes from Selected Native Population in Amasya Province. The African Journal of Biotechnology 10(74): 16763-16768.

Kodad O, R Socias i Company and M Sindic (2014) Kernel Quality in a Local Walnut (juglan sregia L.) Population Grown under Different Ecological Conditions in Morocco. FAO-CIHEAM - NucisNewsletter, Number 16, p 27-31.

Lansari A, E Hassani, D Nabil and E Germain (2001) Preliminary Results on Walnut Germplasm Evaluation in Morocco. Acta Horticultura 544: 27-35.

McGranahan GH and C Leslie (1990) Walnuts (Juglans). Acta Horticultura, 290: 905-951.

Sharma RM, K Kour, B Singh, S Yadav, N Kotwal, JC Rana and R Anand (2014) Selection and Characterization of Elite Walnut (Juglans regia L.) Clone from Seedling Origin Trees in North Western Himalayan Region of India. Australian Journal of Crop Science 8(2): 257-262.

UPOV (1999) Guidelines for the Conduct of Tests for Distinctness, uniformity and stability. Walnut (Juglans regia L.), Geneva: International Union for the Protection of New Varieties of Plants. 